\title{
Successful Employee Empowerment: Major Determinants in the Jordanian Context
}

\author{
Khadra DAHOU, Ishaq HACINI**
}

Received: December 5, 2017

Revised: April 4, 2018

Accepted: April 30, 2018.

\begin{abstract}
Being the most important asset, the human resource represents today the source of the organizations' sustainable competitive advantage. This focus on the employee as the organizations' core of human capital management drives the current interest in empowerment. This paper explores the concept of employee empowerment and the main influential factors in implementing an empowerment initiative: job design, transformational leadership, decision-making authority, continuous training and development, sharing information, and self-managed teams. Using a hypotheses testing approach, this correlational cross-sectional field study investigates the influence of the six factors on the adoption of employee empowerment. Using a questionnaire method, data was collected from Jordanian commercial banks. The results of a multiple linear regression analysis revealed that sharing information, job design, transformational leadership and decision making authority have a positive effect on employee empowerment. Sharing information and adopting the appropriate job design inside the organization have the strongest influence in that fostering these initiatives would certainly make banks' employees' empowerment successful. The research provides insights into the perception of employee empowerment in the Jordanian context, specifically in the banking industry, a high service- oriented sector where empowering employees become a must for a better customer service.
\end{abstract}

Keywords: Employee Empowerment, Job Design, Transformational Leadership, Decision Making Authority, Sharing Information.

JEL Code Classification: C12, D23, M12

UDC: 331.108

DOI: https://doi.org/10.17015/ejbe.2018.021.03

\footnotetext{
* Associate Professor, Faculty of Economics and Management, University of Mascara, Algeria.

E-Mail: dahou.khadra@yahoo.fr

Associate Professor, Faculty of Economics and Management, University of Mascara, Algeria.

E-Mail:ishaq_zida@yahoo.fr

Copyright @ , 2018 Ala-Too International University.
} 


\section{Introduction}

Over the past decade, contemporary organizations witnessed rapid continuous changes in the corporate environment. In order to remain competitive, today's organizations must attain higher levels of performance either in quality, cost or speed. According to Senn (1988), the greatest source of the organizations' competitive edge is their competent, talented, motivated, committed and conscientious employees (Fadal, 2003).

Those Employees are the cornerstones of the success of the organizations as it relates to human-based capital. Both managers and employees have interest in organization's survival and success, and present the change agents who make difference, add value, and get higher performance and competitiveness.

The research found that companies practicing empowerment and have highly committed employees experienced greater benefits like increasing creativity and innovation and higher productivity (Ramesh \& Kumar, 2017; Celik, Iraz, Cakici, \& Celik, 2014). Today's customers and competition require fast, flexible responses, and there is little or no slack in the organization and its relationship to the marketplace, which force employees to decide and act in "real time".

Because of the importance and the direct strategic role of human resources in business, raises the importance of the idea of employee empowerment as an employment strategy within the general business strategies. Therefore, empowering employees in their jobs, delegating to them the responsibilities of their decisions and providing them more autonomies in choosing the way the business is done will have a great impact on their absenteeism, the turnover, their professional satisfaction, their citizenship, their productivity, and thus on the organizations' performance.

Generally, empowerment is the shifting of authority and accountability for decision making and performance of work tasks from managers to employees who perform daily the work. Through this study, researchers have the interest to investigate the major determinants of a successful implementation of an employee empowerment initiative.

In addition, Jordan is a Middle East country, has a high power distance score where "subordinates expect to be told what to do and the ideal boss is a benevolent autocrat.". ${ }^{1}$ So, testing the research model in such working environment would provide insights about readiness and perceptions of Jordanian employees in the banking sector to adopt the initiative of employee empowerment.

The model was developed to include six factors, where results show greater evidence about the validity of these factors in making empowerment successful, encompassing (Spreitzer, 1995, 1997; Gorden, 1995; Guillory \& Galindo, 1996;

\footnotetext{
${ }^{1}$ See: https://www.hofstede-insights.com/country-comparison/jordan/
} 
Honold, 1997; Appelbaum \& Honegger, 1998; Molleman, Delft \& Slomp, 2001; Fadal, 2003; Ozaralli, 2003; Matthews Diaz \& Cole, 2003; Turner, 2006; Ollikainen \& Varis, 2006; Yulk \& Becker, 2006; Gill, Fizgerald, Bhutani, Mand, \& Sharma, 2010) :

- Job design where complex challenging flexible work, especially in customer services, permits employees a chance to take initiatives and feel selfdetermination and importance;

- Transformational leadership by a charismatic leader who inspires employees, excites and motivates them around a shared vision, intellectually stimulate them, and considered each employee as unique;

- Decision making authority by giving employees the opportunity to make their own job decisions with the proper actions;

- Training and development by enhancing their competencies and skills necessary to carry out additional responsibilities and activities with high performance. A training and development program motivates employees intrinsically, diversifies their competencies portfolio and increase their feelings of job security and career development and management.

- Information sharing about the organization's vision, mission, strategy, objectives and the action plan with all employees. Information has to reach to employees, giving them the possibility to participate in the organization's management, problem-solving and strategic objectives realization.

- Self-managed teams where organizations shift their management from focusing on employees to focusing on teams, because of the many benefits teams can provide such as the greater performance, improved problem solving possibilities, and higher motivation.

Thus, the purpose of this study is to develop an empowerment initiative adoption model and testing it in the context of the commercial banks in Jordan. To achieve this, the following objectives are proposed:

- Give insights into the notion of employee empowerment.

- Investigate the influence of job design, transformational leadership, decisionmaking authority, training and development, sharing information, and selfmanaged teams; on the success of employees' empowerment.

- Explore the level of empowerment in Jordanian Commercial banks.

- Approve the reality of the importance of adopting empowerment as a strategic HRM approach and analyze this reality in Jordanian Banks.

\section{Theoretical Framework and Hypotheses Development}

Today's businesses have adopted the modern management practices and turn away the traditional bureaucratic methods. The high-performance initiatives such as employee involvement, total quality management (TQM), teams, and participative work systems have become prominent managerial practices. These strategies are in some way and degree built on the employee empowerment. 
One technique of employee involvement, as a strategy given to employees more responsibility and accountability, is the use of empowerment which involves prompting the authority to make decisions down to the first level of qualified people in the organization.

Understanding what empowerment is, the different models of empowerment and the steps for its implementation is the first major task on the road to real empowerment. Thomas and Velthouse (1990) defined empowerment more broadly as increased intrinsic motivation manifested in a set of four cognitions, reflecting an individual's orientation to his or her work role. It is a situation in which a supportive and interactive environment encourages employees to seek out and implement more efficient business methods (Herrenkohl, Judson, \& Heffner, 1999). According to Wilkinson, empowerment would commonly be associated with the redistribution of power, but in practice, empowerment is usually seen as a form of employee involvement, designed by management and intended to generate commitment and enchain employee contributions to the organization. (Ollikainen \& Varis, 2006).

Some organizational practitioners define empowerment as the process of encouraging employees, including management, to utilize their skills and experience by giving them the power to use more judgment and discretion in their work. It provides employees with enough authority, resources, and latitude to be able to work effectively (Eccles, 1993). Empowerment means "turning the frontline loose", encouraging and rewarding employees to exercise initiative and imagination: "empowerment in many ways is the reverse of doing things by the book". A more explicit definition by Jan Carlzon views empowerment as freeing someone from rigorous control by instructions, policies, and orders, and giving the individual a freedom to take responsibility for his/her ideas, decisions, and actions. It is to release hidden resources that would otherwise remain inaccessible to both the individual and the organization (Melhem, 2004).

Empowering people is also seen as giving them authority and responsibility to make decisions affecting their work. They take responsibility for their actions and work free from the petty bureaucratic hassles that diminish value and waste time (Ollikainen \& Varis, 2006). To empower is to give power, open up and to release the potential of people; embracing job involvement, job enrichment and participation of people in various forms.

In order to understand employee's perception of empowerment, the research of Greasley, Bryman, Dainty, Price, Naismith, and Soetants (2008) found that they don't recognize effectively this term. But employees typically want some empowerment in the form of control, authority, decision making and problem-solving. In term of power, they didn't associate themselves with it. Understanding this employees' perception would give insights on empowerment approach. 
Stark (2005) offers six benefits to empowering the workforce: (a) employees feel that they are valued, (b) workers are able to make better decisions, (c) employees feel a greater responsibility associated with making decisions, (d) employees engage in future problem solving, (e) morale and motivation increase, and (f) managers are able to contribute in other areas. In a study of perceptions of empowerment at the management level, Spreitzer (1995) identified two consequences of empowerment: managerial effectiveness and innovative behaviors. (Turner, 2006)

Many reasons cover the strategic decision of empowering employees. These can be categorized into "(a) a moral responsibility for the well-being of the workforce, or (b) the belief that empowerment will directly or indirectly enhance the financial bottom line" (Turner, 2006, p.8). Also, one of the most important benefits of implementing an empowerment initiative is that an empowered workforce increases adaptability and flexibility to the external environment. This alignment combined with increased flexibility and greater autonomy allows workers to solve their own issues and work with customers and suppliers to meet and exceed expectations (Turner, 2006, p.9).

Empowerment is viewed from two perspectives: "Structural empowerment" or "Psychological empowerment":

Structural empowerment refers to organizational policies, practices, and structures that grant employees greater latitude to make decisions and exert influence regarding their work (Mills \& Ungson, 2003; Greasley et al., 2008). The structural dimension of empowerment views empowerment in terms of a power redistribution model, whereby power equalization produces trust and collaboration. Researchers have identified organizational practices and structures that devolve power through knowledge and skill development, access to information, support, resources and responsibility as empowering.

Other organizational structures that assist the growth of empowerment are: having access to information, receiving support, having access to resources necessary to do the job, and having the opportunity to learn and grow. Jobs that provide discretion and are central to the organizational purpose help employees to gain access to these empowering structures and are the sources of formal power (Kanter, 1977). Kanter (1977) said that empowerment results from decentralization, a flattening of hierarchy, and increased employee participation. On the other hand, employees with strong networks with peers, superiors, and other organizational members are recognized as having informal power with the increased access to empowering structures.

Psychological empowerment identifying the main empowerment's dimensions, reasons for adopting such practice and the facilitating factors are the content of the psychological empowerment theories (Yulk \& Becker, 2006). Psychological empowerment is "conceptualized as the increased task motivation that results 
from an individual's positive orientation to the work role" (Yulk \& Becker, 2006, p.211). Four dimensions of empowerment are identified: meaningfulness, competence, choice, and impact; and the higher an individual "scores" in each of these elements, the greater the sense of empowerment (Thomas \& Velthouse, 1990; Yulk \& Becker, 2006).

Meaningfulness is about the extent to which an individual values a given task, and that regarding his own values and norms (Thomas \& Velthouse, 1990; Yulk \& Becker, 2006).

Competence is about the extent to which an individual possesses the necessary skills and qualifications to accomplish the job's tasks and activities.

Choice refers to the causal responsibility for a person's actions and whether the behavior is perceived as self-determined (Yulk \& Becker, 2006, p.211).

Impact is the extent an individual fulfills the task objectives, affecting the work outcomes (Yulk \& Becker, 2006).

The higher an individual "scores" in each of these elements, the greater the sense of empowerment.

In an attempt to discover and identify the key drivers and antecedents of an empowerment process, tremendous researches have been conducted.

Lashley and McGoldrick (1994) studied the notion of employee empowerment. They analyzed critically the place of empowerment as an empowerment strategy within the general business strategies of hospitality operators. They investigated the development of models of empowerment with different constructs, and have taken into study task dimension, task allocation, power, commitment, and culture as dimensions. Researchers assessed the value of these models in defining the extent and form of empowerment in the hospitality business.

Honold (1997) has given a large literature about empowerment; and found that only when the multi-dimensional approach is taken, will the organization become empowering: leadership, team and collaborative working, arrangements, personal perspective of responsibility, decentralized structure, and contingent reward system.

Fadal (2003) studied employee empowerment as an integral piece driving success and growth of any company, indicating that continuous training and development, grating participation rights and decision- making authority to employees represent the variables that would influence an empowerment initiative. Ozaralli (2003) investigated transformational leadership in relation to empowerment and team effectiveness. She found that transformational leadership contributes to the prediction of subordinates' self-reported empowerment and that the more a team's members experience team empowerment, the more effective the team will be. 
In his turn, Melhem (2004) found that trust, communication, knowledge, and skills were the most significant influencers on the empowerment of service employees. Greasley et al. (2005) showed that leadership and especially the immediate supervisory was of strong influence on diffusing empowerment.

Turner (2006) investigated the relationships between perceptions of leadership, the span of control and industry type on perceptions of employee empowerment. He found that organizational design and industry type may affect empowerment initiatives. According to Yulk \& Becker (2006), job design, intrinsic motivation, participative leadership, organization structure, reward systems, access to information, organizational culture and leader selection and assessment are the most effective for an empowerment success. They add that employee stock ownership plans, sharing information, sharing power through the parallel structure, self-managed teams, democratic decision processes are also practices leading to successful empowerment program.

Another study aiming at examining some of the antecedents and consequences of psychological empowerment found that access to information; employee participation, job security, and supervisory social support were the main antecedents (Bardin, Bartram \& Casimir, 2007). Klidas, Van den Berg and Wilderom (2007) tested four potential practices of the behavior of empowered employees when delivering customer's service which are: training, rewards practices, organizational culture perceptions, and management style. Results showed that the two means of control customer-oriented culture and empowering management style correlated significantly with empowered behavior. Greasley, Bryman, Dainty, Price, Naismith and Soetants (2008), in order to understand employee's perception of empowerment, found that they don't recognize effectively this term. But employees typically want some empowerment in the form of control, authority, decision making and problem-solving.

Baird and Wang (2010) indicated that teamwork, training, and link to rewards had the significant impact on the adoption of employee empowerment. Ro and Chen (2010) research indicated the positive effect of employees' customer orientation and organizational factors (training, reward system and service standards communication) on the success of the empowerment program implementation. Gill et al., (2010) have emphasized the important impact of the transformational leadership on the employees' desire for empowerment.

Kumara (2014) presented empowerment as a strategy the financial organizations/banks have to adopt in order to provide better customers services, gaining their loyalty, and thus increase productivity.

Meningen (2017) found that the presence of high-involvement work processes and entrepreneurs' attitudes towards participative decision-making relate significantly to the employee empowerment dimension of impact. Ramesh and Kumar (2017) made a review on employee empowerment. They cited steps to empower 
employee (by identifying the reasons for empowerment, choosing the employees themselves, providing role information, sharing information, training employees and inspiring initiatives). The researchers emphasized on the outcomes of employee empowerment: encouraging creativity and innovation, increasing productivity, enhancing the work's quality, helping employee retention, which lead to the achievement of the organizations' competitive advantage. Roozitalab and Majidi (2017) found that designing appropriately the jobs, adopting a transformational leadership, managing knowledge and providing organizational support influence the improvement of employees' empowerment.

In this research and based on the previous review of the literature, six factors are identified as determinants of successful employee empowerment initiative: job design, transformational leadership, decision making authority, continuous training and development, sharing information and self-managed teams.

\subsection{Empowerment and Job Design}

The more non-routine, unrepetitive, enriched and challenging are the jobs, the more are increased the empowerment opportunities. In addition, in the service sector, empowerment is allowed, especially when interacting directly and consistently with customers (Yulk \& Becker, 2006). Job enlargement and job enrichment are the two primary building blocks of jobs design which encourage and motivate employee empowerment.

- Job enlargement: Pertains especially to the addition of operational tasks (Hackman \& Lawler, 1971). This creates opportunities to integrate sequential tasks. job enlargement is believed to contribute potentially to efficiency, quality, multifunctionality as a buffer of capacity and then flexibility. It also contributes to task variety and task identity, which provides a sense of completeness and increases the meaningfulness of a job (Hackman \& Oldham, 1980). It is likely that this will improve the quality of working life and the motivation of workers also. (Molleman et al., 2001).

- Job enrichment: Pertains to the delegation (or "vertical decentralization" in terms of Mintzberg, 1979) of control tasks (Cunningham \& Eberle, 1990). Control tasks pertain to the reconsideration of operational tasks. According to Hackman and Oldham (1980), autonomy with respect to local decision making has an even stronger motivating potential than job enlargement. Besides, job enlargement and job enrichment often go hand in hand, that is, the addition of an operational task is often accompanied by the addition of other elements of the cycle to which that task belongs. (Molleman et al., 2001).

Jobs can be made more intrinsically motivating by redesigning work so that employees have control over tasks typically performed by supervisors. Five characteristics are essential to all jobs in order to have intrinsically motivating work (Hackman \& Oldham, 1980). "Task identity" is the degree to which the individual performs a whole piece of work" (Yulk \& Becker, 2006, p.212). "Task significance" is 
the extent to which the work has an influence on others (Yulk \& Becker, 2006). "Skill variety" is the polyvalence of the individual's skills, forming his skills' portfolio. "Autonomy" is to what extent an individual takes initiative and acts freely in his job, taking responsibility for his outcomes. "Feedback" is level of information sharing about an individual job's results and activities and objectives fulfillment (Yulk \& Becker, 2006).

Spreitzer (1995) found some characteristics of job design which could be related to employees' empowerment: low role ambiguity as well as access to information about the unit's workflow, performance and productivity and the firm's external environment, mission, strategy and vision (Spreitzer, 1995 \& 1996; Appelbaum \& Honegger, 1998). Thus, the researchers hypothesize the following:

\section{H1: Job Design has a direct significant impact on employee empowerment.}

\subsection{Empowerment and Transactional Leadership}

The goals of empowerment and the aims of leadership are to move the energy to the front line by transferring appropriate amounts of decision making, responsibility, and accountability downward.

Recently the focus has shifted from the traditional transactional leadership to transformational leadership as the ability of a leader to influence the values, attitudes, beliefs, and behaviors of others by working with and through them to accomplish the organization's mission. Bass (1985) said that transformational leadership would result in followers performing beyond expected levels of performance as a consequence of the leaders' influence, through raising awareness of the outcomes and by developing intellectually stimulating and inspiring followers to transcend their own self-interests for a higher collective vision. Roueche, Baker, and Rose (1989) defined transformational leadership in terms of the ability of a leader to influence the values, attitudes, beliefs, and behaviors of others by working with and through them to accomplish the organization's mission. Also, Hater \& Bass (1988) stated that the dynamics of transformational leadership involve strong personal identification with the leader, joining in a shared vision of the future, or going beyond the self-interest exchange of rewards for compliance. (Ozaralli, 2003). Bass (1985) identified four dimensions of transformational leadership: (a) charisma, (b) inspirational motivation, (c) intellectual stimulation, and $(d)$ individualized consideration.

The qualities of a transformational leader are strikingly close to the basic tenets of empowerment, and that what many studies tried to uncover like Gill et al., (2010). In addition to appearing similar to empowerment, the presence of transformational leadership has been found to positively relate to job satisfaction, extra-role behaviors, and perceived extra effort (Bryman, 1992; Turner, 2006). Here, the researchers hypothesize that:

H2: transformational leadership has a strong impact on employee empowerment. 


\subsection{Empowerment and Decision making Authority}

Decision making Authority is an important part of empowering employees as stated by Guillory and Galindo (1996):" the determining of successful companies ... will be flexible decision making based on a shared strategic vision. This means delegating decision making powers to middle managers and line managers, with stifle selfdirected operation". Matthews Diaz \& Cole (2003) have written about what they called "control of the workplace decisions" which is defined as occurring when employees are allowed input into all aspects of their professional career. According to Wilkinson (1998), for there to be a perception of empowerment, individuals and teams must have control over diverse responsibilities such as scheduling, the hiring of new employees, staff development, as well as goal setting. Quinn and Spreitzer (1997) state that it is necessary for employees/teams to feel that they have discriminatory power in decision making. To increase control of workplace decisions, companies should endeavor to allow employees control over decisions when it is possible. Patterson, Grenny, McMillan and Switzler (1996) supported the need to grant or involve employees in the decision making process and said "Given that opportunities now exist for choice ... those affected by the decision should be involved in it".

In line with the importance of empowering employees with the authority to make functional business-related decisions rather than using positional power only, Nelson (2001) said "Seldom is anyone given enough authority to make actions necessary to improve things in their jobs all by themselves. The best authority today is not the formal authority of position" (Fadal, 2003). So, the third hypothesis is:

H3: Decision-making authority has a strong impact on employee empowerment.

\subsection{Empowerment and Training and Development}

Training is probably the most frequently used "intervention" when considering what is crucial in the implementation of empowerment.

The aim of training is the development and enhancement of the skills necessary for employees to be able to handle their increased authority and responsibility effectively and to exercise good judgment. Effective training generally supports the goal of empowerment by enhancing morale and motivation, increasing flexibility, reducing staff turnover, and allowing employees to function independently without the need for constant supervision. Supporting the need for the organizations to embrace training as an empowerment core business strategy, McLagan and Nel (1995) said: "Training and development have a positive effect on business financial performance ... companies that combine group economic participation, intellectual participation, and flexible job design, and training and development get an added productivity boost, two-thirds of the difference, observed in bottom-line impact was due to combined effects of these practices". 
Nicholls (1995) proposed a three-stage training framework reflecting that empowerment occurs as the organizations engage with people and they respond to this engagement. The first stage is for the manager as an enabler, the second as coaching enabler and the third as visionary enabler creating a climate of commitment through a sense of belonging and excitement.

Guillory \& Galindo (1996) speaking on the value of training and development as an empowerment strategy said: "Personal growth drives expanded empowerment and ... development occurs most effectively where managers encourage training, interactive mentoring and professional growth opportunity". Companies are beginning to accept the fact that they must empower their employees through training and development because of the benefits associated with it (Fadal, 2003). Then, the fourth hypothesis is as follow:

H4: Training and development influences significantly employee empowerment.

\subsection{Empowerment and Sharing Information}

Essential for an empowerment initiative, sharing the business information is very important for employees, about the business vision, strategies, objectives and action plans. This would facilitate the organization's work with meaningful employees' contributions (Yulk \& Becker, 2006). If the information is not diffused and shared within the organization, employees can't behave responsibly and participate in decision-making processes. Conger and Kanungo (1988) provide several examples that might impede an employee's sense of information sharing, including poor communication structure, lack of knowledge of necessary resources, and lack of understanding of how rewards are distributed.

The organization must clearly communicate the company's vision, strategy, objectives, goals and directions. Randolph (1995) maintains that information sharing is a critical and often the least understood component of empowerment. If the information is not shared, then employees are not able to behave responsibly. (Matthews, Diaz \& Cole, 2003). The organizations must diffuse information and provide access to all employees if it aims to empower them and get the desired results from initiating an empowerment strategy. This is why researchers develop the following hypothesis:

\section{H5: Sharing information has a strong impact on employee empowerment}

\subsection{Empowerment and Self-managed Teams}

The team concept of empowerment probably developed out of the quality circle efforts of the 1970s and 1980s (Sims \& Manz, 1986). Empowerment from this perspective is "an act of building, developing, and increasing power through cooperating, sharing, and working together" (Rothstein, 1995, p. 21). It means managing organizations by collaboration where workers have a voice (Gorden, 1995; Honold, 1997). Teams help all members of the organization feel responsible for co-creating a workplace they can believe in and thrive in; a workplace that 
enables them to provide more high-quality products and improve problem-solving abilities. Work teams can also have greater worker motivation, increased participation and more power equalization (Ollikainen \& Varis, 2006).

Such type of teamwork is suitable for projects management, requiring higher polyvalent integrated competencies. To develop self-managed teams, Yulk and Becker (2006) proposed some required antecedents: “(1) clearly defined objectives, (2) a complex and meaningful task, (3) a small team size and stable membership, (4) substantial team discretion over work processes, (5) access to relevant information, (6) appropriate recognition and rewards, (7) strong support by top management, (8) members who have strong interpersonal skills, and (9) a competent external leader who serves as a liaison with formal management and other teams". Based on that, the final hypothesis is as follow:

H6: Self-managed team has an impact on employee empowerment.

Based on the theoretical review presented as the research background above, researchers proposed the following model:

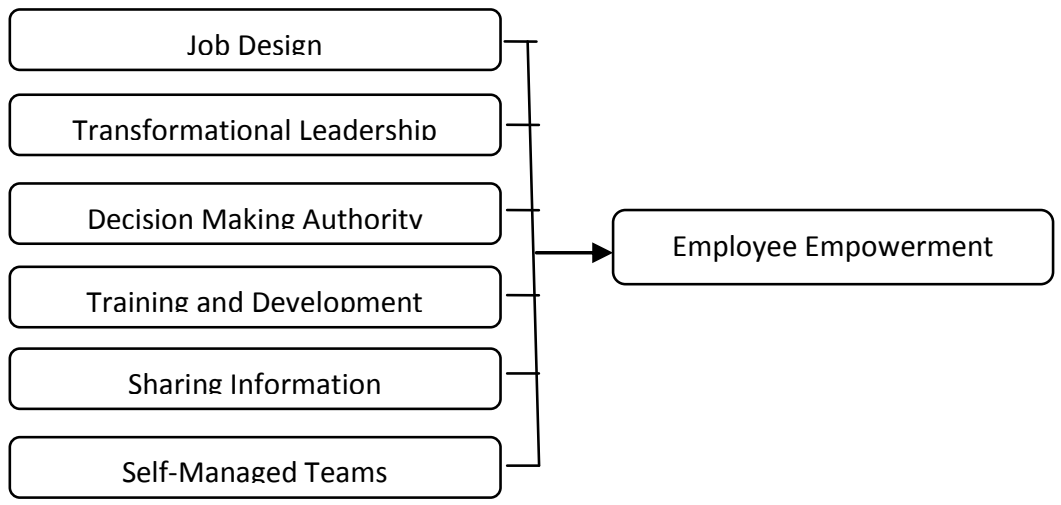

Figure 1. Research Model

\section{Research Methodology}

This cross sectional study is a hypothesis testing, trying to explain the nature of the relationship between major indicated factors and their influence on the implementation of an employees' empowerment initiative. To find an answer to the issue at hand, this research needs to use a correlational study, studying the correlation between employee empowerment and the six factors: job design, transformational leadership, decision-making authority, training and development, sharing information and self-managed teams.

This study represents a field study conducted in Jordanian commercial banks which represent the unit of analysis, encompassing: Bank of Jordan, SociétéGénérale 
Jordan, Jordan Islamic Bank, Jordan Kuwait Bank, Jordan Ahli Bank, Arab Bank, National Microfinance Bank, and Jordan Islamic Bank for Finance and Investment.

In addition to the ease of access, the choice of those banks was because of their high service-oriented nature, where in-front employees are "the voice and the face" (Timothy \& Abubakar, 2003, p.36) of the banks, and succeeding their deals and gaining their customers' satisfaction and loyalty depend on the performance of those frontline employees: "Most service organizations and employers consider customer service as a key factor in their business success formula, but very few appreciate the importance of empowered employees in attaining their goal. No organization/bank can provide exceptional, quality customer service without empowering their employees. The coordination between employees and employers is very important in this context."(Kumara, 2014, p. 194)

As a sampling approach, data was gathered from a probability sample of respondents. The sample was selected on the basis of simple random sampling. Employees working in the banks represent the population of the study. A questionnaire is developed to collect data from the targeted population.

\subsection{Measurement}

The measurement of items was taken from previous studies and merged items with the same meaning. The items for the study's variable "Job design" were developed from (Appelbaum \& Honeggar, 1998; Molleman et al, 2001; Yulk \& Becker, 2006) covered by 4 items. For "transformational leadership", 7 items covered the variable and were taken from (Seaborne, 2003; Bodner, 2005; Newman, 2001). For training and development and decision making authority, items were taken from (Fadal, 2003) from which 3 items cover the variable of decision making authority and 5 items for training. Sharing and information, 5 items were taken from (Melhem, 2004; Matthews, Diaz \& Cple, 2003). For the self-managed team, 5 items were taken from (Yulk \& Becker, 2006). Finally, for employee empowerment, items were taken from (Melhem, 2003; Bodner, 2005; Seaborne, 2003; Yulk \& Becker, 2006; Klidas et al., 2007). It was covered by 18 items. Each item was surveyed directly on a five-point Likert type scale with scales named in the following manner: " 1 " strongly disagree, " 2 " disagree, " 3 " neutral, " 4 " agree, " 5 " strongly agree.

\subsection{Data Collection}

As said before, a questionnaire is developed to collect data, where respondents were asked to select the appropriate responses.

The questionnaire was translated to the Arabic language to become more understandable. A total of 230 questionnaires were distributed directly (personally), 113 were recuperated and valid for analysis. (56.6\%) of the respondents were male and (43.4\%) were female. The respondents ranged in age from 20 to 50 with (46.9\%) between 20 and 29, and (36.3\%) between 30 and 39, and only (16.8\%) have 40 and more. 
Most of the respondent has a BA (91.2\%), working in functional level (56.6\%) with (48.7\%) having a tenure or service of 3 to 6 years, and win between 200-400 JDs (42.5\%), between $400-600$ JDs (31.9\%) and $25.7 \%$ have a pay more than 600 JDs. Detailed descriptive statics relating to the respondents' characteristics are shown in table 1.

\section{Table1. Descriptive statistics of respondents' characteristics}

\begin{tabular}{llcc}
\hline Measure & Value & Frequency & Percentage\% \\
\hline \multirow{2}{*}{ Gender } & Male & 64 & 56.6 \\
& Female & 49 & 43.4 \\
\hline \multirow{3}{*}{ Age } & $20-29$ & 53 & 46.9 \\
& $30-39$ & 41 & 36.3 \\
& 40 and more & 19 & 16.8 \\
\hline \multirow{2}{*}{ Academic } & B.A & 103 & 91.2 \\
Qualification & Master & 9 & 8.0 \\
& P.H.D & 1 & 0.9 \\
\hline \multirow{4}{*}{ Job Status } & Branch director & 7 & 6.2 \\
& Chief assistant & 17 & 15.0 \\
& Chief executive & 25 & 22.1 \\
\hline \multirow{3}{*}{ Revenue } & Functionary & 64 & 56.6 \\
& 200-400 JD & 48 & 42.5 \\
& $401-600$ JD & 36 & 31.9 \\
\multirow{2}{*}{ Tenure } & Over 600 JD & 29 & 25.7 \\
& $3-6$ & 55 & 48.7 \\
\hline
\end{tabular}

\section{Data Analysis And Results}

\subsection{Reliability}

The reliability for this study was measured by using Cronbach Alpha-coefficient. The values range from $61.8 \%$ (Decision-making authority) to $89.8 \%$ (Transformational leadership). All variables in our research model demonstrated acceptable reliability (more than 60\%). These coefficients are represented for each of the variables in Table 2

Table2. Reliability

\begin{tabular}{lc}
\hline Variables & Cronbach's alpha \\
\hline Job Design & $67.5 \%$ \\
Transformational Leadership & $89.8 \%$ \\
Decision-making authority & $61.8 \%$ \\
Training and Development & $86.3 \%$ \\
Sharing Information & $70.6 \%$ \\
Self-managed team & $85.1 \%$ \\
Employee Empowerment & $86.8 \%$ \\
\hline
\end{tabular}




\subsection{Hypothesis Testing}

As shown in table 3, from the results, the six factors are significantly correlated to employee empowerment. This correlation was high between employee empowerment and transformational leadership (62.4\%), and the lowest correlation was between employee empowerment and job design by (42.2\%).

Table 3. Correlation between research independent and dependent variables

\begin{tabular}{ccccccc}
\hline \multirow{2}{*}{ Empowerment } & Job design & Trans.Lead & Decision & T\&D & Info & Team \\
\cline { 2 - 6 } & $.726^{* *}$ & $.746^{* *}$ & $.674^{* *}$ & $.757^{* *}$ & $.758^{* *}$ & $.640^{* *}$ \\
\hline
\end{tabular}

**. Correlation is significant at the 0.01 level (2-tailed).

In order to test the research hypotheses, a stepwise multiple linear regression was conducted which exhibits which of the research independent variables impact on employee empowerment and order them. Results of this test are shown Table 4.

Table 4. Stepwise Multiple Regression Results

\begin{tabular}{lccc}
\hline R-squared: .760 & & F-statistic: 85.430 & \\
Adj R-squared : .751 & Probability: 0.0000 & \\
\hline Variable & Coefficient & T-Statistic & Probability \\
\hline Sharing Information & .254 & 4.763 & .000 \\
Job Design & .252 & 5.218 & .000 \\
Transformational Leadership & .167 & 3.293 & .001 \\
Decision Making Authority & .110 & 2.181 & .031 \\
\hline
\end{tabular}

The results indicate that $\mathrm{R}^{2}=76 \%$, significant at $1 \%$. This means that $76 \%$ of the variance in the dependent variable "employee empowerment" is explained by the four main independent variables that were found capturing and affecting employee empowerment: sharing information, job design, transformational leadership and decision making authority. So, these results make $\mathrm{H} 1, \mathrm{H} 2, \mathrm{H} 3$, and $\mathrm{H} 5$ accepted, supported and substantiated where sharing information ( $(=25.4 \%)$ and job design $(\beta=25.2 \%)$ have approximately the same and highest impact on the success of employee empowerment, followed by transformational leadership ( $(=16.7 \%)$, and finally decision making authority $(\beta=11 \%)$. Training and development and selfmanaged teams were found to have no impact on employee empowerment initiative success in the Jordanian commercial banks, which reject $\mathrm{H} 4$ and $\mathrm{H} 6$.

\subsection{Discussion}

Much research has been established on employee empowerment, searching to uncover the major strategies that organizations have to adopt when fostering such approach and the different variables or factors that can influence its implementation. In this study, the researchers have taken the main factors, leading to an affecting implementation of employee empowerment initiative. These factors represent job design, transformational leadership, decision-making authority, continuous training and development, sharing information, and self-managed 
team. The researchers have chosen these factors as independent variables based on the great number of studies and dissertations that the researchers have profited from, getting more insights on the subject of employee empowerment.

From results shown above, it appears that job design is perceived having a significant direct positive effect on employee empowerment, which means employees in banks saw that banks have to make jobs more challenging and continually enrich or enlarge jobs to motivate employees and succeed in empowering them. This was supported by (Appelbaum \& Honeggar, 1998; Molleman et al.,2001; Yulk \& Becker, 2006; Roozitalab \& Majidi, 2017).

Transformational leadership is perceived as having a significant positive effect on employee empowerment and which was predicted because of the huge number of studies taking transformational leadership as the appropriate leadership style that an organization has to adopt when adopting an empowerment initiative. This was supported by (Bass, 1985; Seaborne, 2003; Bodner, 2005; Newman, 2001; Ozaralli, 2003; Bryman, 1992; Turner, 2006; Roozitalab \& Majidi, 2017).

Decision-making authority has an effect on employee empowerment. Of course, this was expected as the most predicted logical antecedent of empowerment. Results support that giving to employees the authority of making their own decisions, would result in a very successful implementation of an empowerment initiative. Nevertheless, this will have great results in term of employee mentality and their organizational involvement and satisfaction. These results were also supported by (Matthews, Diaz \& Cole, 2003; Wilkinson, 1998; Quinn and Spreitzer, 1997; Guillory and Galindo, 1996; Graham \& Titus, 1979; Patterson et al., 1996; Nelson, 2001; Fadal, 2003)

Findings also support the idea that to empower employees, the organization has to give them access to information, making them knowledgeable about all what happens inside. Jordanian banks' employees perceived getting access to information and sharing it, and diffusing up to date information within banks would greatly support and facilitate the implementation of an empowerment initiative within Jordanian context. This idea was supported by (Yulk \& Becker, 2006; Ollikainen \& Varis, 2006; Conger \& Kanungo, 1988; Randolph, 1995; Matthews, Diaz \& Cole, 2003)

Evidence shows that the Jordanian commercial banks depend more on sharing information and job design, less than practicing transformational leadership and giving authority in making-decision in empowering employees, while training and development and self-managed teams have no effecting in making this initiative successful. These findings support the results of Melhem (2004) taking his study in financial services and suggest that banks have a great steady to adopt the employee empowerment as a strategy where each member of the organization has a say and contribution in realizing it. 


\section{Conclusion}

Until now, empowerment has been attracted the interest of a huge number of studies and research, for the major and important antecedents of organizational involvement, employee satisfaction, decreased turnover, and all advantages that can be realized when adopting such strategy. This is why; the researchers were interested in investigating the main strategies or steps that organizations have to apply before initiating this approach.

Researchers have distracted six main factors as the major considerations to take into account when empowering employees: appropriateness of job design, practicing transformational leadership style, giving authority of making the decision, providing employees with continuous training and development, sharing information with them, and finally, building self-managed teams inside the organization. Search findings, consistent with previous studies, revealed that four factors are perceived as tools to empower employees in Jordanian commercial banks: sharing information, job design, transformational leadership and decision making authority, while training and development and self-managed teams had no effect on empowering employees. They indicate that Banks keen to share their information with their employees keeping them in tune with what's going on inside and outside the organization. They also indicate that banks focus on designing appropriately the jobs, adopting a more transformational style when leading employees, giving them more decision making authority.

This search is one attempt, aiming to investigate the extent to which Jordanian banks apply and adopt empowerment as one of the new approaches in the field of Human Resource Management, giving insights to the strategic role that can such strategies of the HRM plays in boosting banks performance: "Empowered working environment enables satisfying the needs of customers and keeps them coming back/loyal, and maintains best relations. This will help banks to reshape in these changing competitive and developing financial markets." (Kumara, 2014, p.198)

Any research has some limitations when studying the subject between hands. In this research, its design is cross-sectional, and investigating the success of an employee empowerment strategy needs longitudinal search. Also, the questionnaire used to collect data does not always provide accurate data and testing this model using qualitative tools giving more accurate results. Finally, researchers have analyzed data from a small sample (113 managers), which would be more appropriate with a wider sample.

Also, researchers have attempted to propose some recommendations based on their research findings. First, Banks' human resource managers have to recognize the centrality importance in adopting an empowerment strategy, and its important antecedents that can be realized for the interest of the organizations. Second, for future research researcher recommends for searching additional factors having an effect on empowering employees in organizations, in addition, it would be reasonable to expand the number of situations to which it applies. 


\section{References}

Baird, K., \& Wang, H. (2010). Employee empowerment: extent of adoption and influential factors. Personal Review, 39(5), 574-599. https://doi.org/10.1108/00483481011064154

Bardin, C., Bartran, T., \& Casimir, G. (2007). The antecedents and consequences of psychological empowerment among Singaporean IT employees. Management Research News, 30(1), 34-46. https://doi.org/10.1108/01409170710724287

Bass, B. M. (1985). Leadership and performance beyond expectations. New York: Free Press.

Bodner, S. L. (2005). Design and empirical analysis of a model of empowering leadership. Unpublished Doctoral Dissertation. University of North Texas.

Bryman, A. (1992). Charisma and leadership in organizations. London: Sage.

Celik, A., Iraz, R., Cakici, A. B., \& Celik, N. (2014). The effects of employee empowerment application on organizational creativity and innovation in enterprises: the case of OIZ. European Scientific Journal, 10(10), 99-107

Conger, J., \& Kanungo, R. (1988). The empowerment process: Integrating theory and practice. Academy of Management Review, 13, 471-482. https://doi.org/10.2307/258093

Cunningham, J. B., \& Eberle, T. (1990). A Guide to Job Enrichment and Redesign. Personnel (AMA), 67(2), 56-61.

Eccles, A. (1993). The deceptive allure of empowerment. Long Range Planning, 26 (6), 13-21. https://doi.org/10.1016/0024-6301(93)90203-R

Fadal, S. (2003). Employee Empowerment as a business optimization technique: utilizing continuous training and development, participation rights and decision making authority. Unpublished doctoral dissertation, Argosy University-orange country, USA.

Gill, A., Fizgerald, S., Bhutani, S., Mand, H.,\& Sharma, S. (2010). The relationship between transformational leadership and employee desire for empowerment. International Journal of Contemporary Hospitality, 22(2), 263-273. https://doi.org/10.1108/09596111011018223

Gorden, W. I. (1995). People should be as important as profits: from enchantment to empowerment. Vital Speeches of the Day, 285-88.

Graham, B. S., \& Titus, P. S. (1979) The amazing oversight: Total participation for productivity. New York: Amacom.

Greasley, K., Bryman, A., Dainty, A., Price, A., Naismith, N. \& Soetants, R. (2008). Understanding empowerment from an employee perspective; what does it mean and do they want it?. Team performance management, 14 (1/2), 39-55. https://doi.org/10.1108/13527590810860195

Greasley, K., Bryman, A., Davity, A., Price, A., Soetanto, R., \& King, N. (2005). Employee perception of empowerment. Employee Relations, 27(4), 354-368. https://doi.org/10.1108/01425450510605697

Guillory, B., \& Galindo, L. (1996). Empowerment: For high performing organizations, Salt Lake City, UT: Innovation International.

Hackman,]. R, \&: Lawler, E. E. (1971). Employee reactions to job characteristics. Journal of Applied Psychology, 55, 259-286. https://doi.org/10.1037/h0031152

Hackman, ]. R., \&: Oldham, G. R. (1980). Work redesign. Reading, MA: Addison-Wesley.

Hater, J. J., \& Bass, B. M. (1988). Superiors' evaluations and subordinates' perceptions of transformational and transactional leadership. Journal of Applied psychology, 73(4), 695. https://doi.org/10.1037/0021-9010.73.4.695 
Herrenkohl, R. C., Judson, G. T., \& Heffner J. A. (1999). Defining and measuring employee empowerment. The Journal of Applied Behavioral Science, 35 (3), 373-389.

Hofstede Insights. (2018). Retrieved from https://www.hofstede-insights.com/countrycomparison/jordan/

Honegger, K., \& Appelbaum, S. (1998). The impact of perceived control and desire to be empowered: analysis of perception and reality. Managing service quality, 8 (6). https://doi.org/10.1108/09604529810235141

Honold, L. (1997). A review of the literature on employee empowerment. Empowerment in organizations, 5(4), 202-212. https://doi.org/10.1108/14634449710195471

Kanter, R. M. (1977). Men and women of the corporation. New York: Basic Books.

Klidas, A., Van den Berg, P.T., \& Wilderom, C.P.M. (2007). Managing employee empowerment in luxury hotels in Europe. International journal of service industry management, 18(1). https://doi.org/10.1108/09564230710732902

Kumara, S. (2014). Dawning of a new era of empowerment a key success factor of service quality in banking in Sri Lanka.

Lashley, C., \& McGoldrick, J. (1994). The limits of empowerment- A critical assessment of human resource strategy for hospitality industry. Empowerment in Organizations, 2(3), 2538. https://doi.org/10.1108/09684899410071671

Matthews, R. A., Diaz, W. M., \& Cole, S. G. (2003). The organizational empowerment scale. Personnel Review, 32 (3), 297-318. https://doi.org/10.1108/00483480310467624

McLagan, P. and Nel, C. (1995). The Age of Participation: New Governance for the workplace and the World. (2nd Ed.). San Francisco: Berrett-Koehler.

Melhem, Y. (2004). The antecedents of customer-contact employees' empowerment. Employee Relations, 26 (1), 72-93. https://doi.org/10.1108/01425450410506913

Meningen, O. V. (2017). Employee empowerment within small and medium-sized enterprises. Unpublished Master Thesis Human Resource Management. Tilburg University.

Mills, P. K., \& Ungson, G.R. (2003). Reassessing the limits of structural empowerment: Organizational constitution and trust as controls. Academy of Management Review, 28 (1), 143-153. https://doi.org/10.2307/30040694

Molleman, E. B., Delft, B. V., \& Slomp, J. (2001). The application of an empowerment model. Human Factors and Ergonomics in Manufacturing, 11(4), 339-354. https://doi.org/10.1002/hfm.1018

Nelson, B. (2001). Please don't just do what I tell you: Do what has to be done. New York: Hyperion.

Newman, K. P. (2001). The impact of leadership style and empowerment of nursing organizational structure. Unpublished Doctoral Dissertation.School of Education, Spalding University.

Nicholls, J. (1995). Getting empowerment into perspective: a three-stage training framework. Empowerment in organizations, 3(2), 6-11. https://doi.org/10.1108/09684899510815483

Ollikainen, M., \& Varis, J. (2006). Human Errors play a remarkable role in sheet metal industry. Mechanika, 5 (61), 51-56.

Ozaralli, N. (2003). Effects of transformational leadership on empowerment and team effectiveness. Leadership \& Organization Development Journal, 24(6), 335-344. https://doi.org/10.1108/01437730310494301 
Patterson, K., Grenny, J., McMillan, R., \& Switzler, A. (1996). The balancing act. Cincinnati: Thomson Executive Press.

Quinn, R., \& Spreitzer, G. (1997). The road to empowerment: Seven questions every leader should consider. Organizational Dynamics, 2, 37-39. https://doi.org/10.1016/S00902616(97)90004-8

Ramesh, R., \& Kumar, K. S. (2017). Role of employee empowerment in organizational development. International Journal of scientific research and management, 2(8), 1241-1245.

Randolph, W. A. (1995). Navigating the journey to empowerment. Organizational dynamics, 23(4), 19-32.

Ro, H., \& Chen, P-J. (2010). Empowerment in hospitality organizations: customer orientation and organizational support. International Journal of Hospitality Management.

Roozitalab, A., \& Majidi, M. (2017). Factors affecting on improvement employee empowerment (Case study: saipa corporation). International Review, (1-2), 9-17. https://doi.org/10.5937/intrev1702009R

Rothstein, L. R. (1995). The empowerment effort that came undone. Harvard Business Review, 20-31.

Roueche, J., Baker, G., \& Rose, R. (1989). Shared vision. Washington, DC: AACC.

Seaborne, W. (2003). An examination of the relationship between leadership style and empowerment. Unpublished Doctoral Dissertation.School of Leadership Studies, Regent University.

Sims, H. P., \& Manz, C. C. (1996). Company of heroes: Unleashing the power of selfleadership. John Wiley \& Sons.

Spreitzer, G. M. (1995). Psychological empowerment in the workplace: dimensions, measurements and validation. Academy of Management Journal, 38, 1442-1465. https://doi.org/10.5465/256865

Spreitzer, G. M., Kizilos, M. A., \& Nason, S. W. (1997). A dimensional analysis of the relationship between psychological empowerment and effectiveness, satisfaction and strain. Journal of Management, 23, 679-704. https://doi.org/10.1177/014920639702300504

Stark, J. (2005). Maturity model for PDM. Product Lifecycle Management: 21st Century Paradigm for Product Realisation, 367-382.

Thomas, K., \& Velthouse, B. (1990). Cognitive elements of empowerment: An "interpretive" model of intrinsic task motivation. Academy of Management Review, 15, 666-681. https://doi.org/10.5465/amr.1990.4310926

Timothy, T., \& Abubakar, H. S. (2013). Impact of employee empowerment on service quality - An empirical analysis of the Nigerian banking industry. British Journal of Marketing Studies, 1 (4), 32-40.

Turner, J.I. (2006). Employee empowerment: relationships between location in the hierarchy, span of control, and industry type on perceptions of empowerment. Unpublished Master dissertation. University of North Texas, USA.

Wilkinson, A. (1998). Empowerment: Theory and practice. Personnel Review, 27(1), 40-56. https://doi.org/10.1108/00483489810368549

Yulk, G.A., \& Becker, W.S. (2006). Effective empowerment in organizations. Organization Management Journal, 3(3), 210-231. 